MAES Esmail, MYZ El-Abdin, M Abd El-Salam, M Yousri Ibrhim, SSM Koraa, E Mahmoud. Pediatric, Al Asher University, Cairo, Egypt

Background Oxidative effects of phototherapy on cell membranes and cell components may have a wide range of potential adverse effects, including .DNA damage. Apoptosis is an indispensable mechanism for maintaining many cellular functions, including cell replication, and removal of damaged cells with high burden of genetic mutations. Many genes function as apoptosis regulatory genes. Examples of these genes include the BCL2 gene which is an anti-apoptotic oncogene, and the BAX gene which acts as a promoter of apoptosis.

Objectives Assess the effect(s) of phototherapy on DNA and on rate of apoptosis in full term neonates with hyperbilirubinemia. It comprised 35 neonates with indirect hyperbilirubinemia who received phototherapy for 48 hours, and 20 apparently healthy full term neonates with normal serum bilirubin level, as a control group. DNA damage was assessed by DNA fragmentation and micronucleus assay. Determination of the anti-apoptotic, (BCL2) protein, and Bax gene expression status.

Results The frequency of micronuclei in circulating lymphocytes of neonates who received phototherapy has significantly increased before and after phototherapy compared to controls. DNA fragmentation in circulating lymphocytes, was significantly higher among cases before and after phototherapy compared to controls. The plasma BCL2 protein was significantly lower in the cases before and after phototherapy compared to controls and Bax gene expression was significantly high among cases before and after phototherapy compared to controls.

Conclusions Phototherapy induces more DNA damage and enhances apoptosis of exposed cells, probably through down regulation of BCL2 expression and upregulation of bax gene expression in neonates with hyperbilirubinemia.

\section{IMPROVING SAFETY OF VASCULAR CATHETER INSERTION IN HIGH-RISK NEWBORNS THROUGH STANDARDIZED TEACHING}

doi:10.1136/archdischild-2012-302724.1551

${ }^{1} \mathrm{KS}$ Lee, ${ }^{2} \mathrm{~A}$ Jefferies, ${ }^{3} \mathrm{M}$ Dunn. ${ }^{1}$ Hospital for Sick Children; ${ }^{2}$ Mount Sinai Hospital; University of Toronto; ${ }^{3}$ Sunnybrook Health Sciences Centre, Toronto, ON, Canada

Background Umbilical and percutaneous central catheter placement in high-risk newborns are common NICU procedures with high complication rates, particularly when inserter experience varies. We developed, implemented and evaluated a standardized catheter insertion training program for NICU clinicians to improve patient safety.

Methods Seventy-one clinicians were surveyed to assess learning needs. Using the results, a program that included a manual, didactic seminars, self-study electronic module, pocket cards and low-fidelity simulation for practice and feedback was developed. Effectiveness was assessed with pre- and post-training multiple choice knowledge tests and Xray quiz focused on recognition and management of catheter malposition, plus a post-training simulation performance test. Malposition of catheters inserted in the NICU was the primary outcome.

Results Real-life practice and simulation were the highest rated teaching methods. Seventy-six clinicians completed at least one program component over 3 months. Post-training knowledge scores $(65 \pm 11 \%$ vs $85 \pm 9 \%, n=65$, mean \pm sd) and Xray scores $(59 \pm 13 \%$ vs $69 \pm 16 \%, n=60)$ improved significantly compared to pre-training $(p<0.01)$. Performance checklist score was $88 \pm 8 \%$. Learner satisfaction was high. Catheter malposition rate decreased from $56 \%$ $(\mathrm{n}=292)$ to $36 \%(\mathrm{n}=374)(\mathrm{p}>0.05)$.

Conclusions A standardized training program resulted in improved knowledge and recognition of catheter malposition but not a significant decrease in malposition rate in the NICU.

\section{IMPROVING CONTROL OF THE OXYGEN SATURATION DURING RESUSCITATION OF PRETERM INFANTS WITH THE USE OF TREND MONITORING}

doi:10.1136/archdischild-2012-302724.1552

${ }^{1,2} \mathrm{~T}$ Goos, ${ }^{2} \mathrm{D}$ Rook, ${ }^{1,2} \mathrm{AC}$ van der Eijk, ${ }^{2} \mathrm{AA}$ Kroon, ${ }^{1} \mathrm{~J}$ Dankelman, ${ }^{2} \mathrm{KM}$ Reiss. ${ }^{1}$ Biomechanical Engineering, Delft University of Technology, Delft; ${ }^{2}$ Pediatrics, Division of Neonatology, Erasmus MC - Sophia, Rotterdam, The Netherlands

Background The European Resuscitation Council (ERC) guidelines prescribe oxygen saturation $\left(\mathrm{SpO}_{2}\right)$ targets for the first $10 \mathrm{~min}$ utes of resuscitation after birth. Unfortunately, the control of $\mathrm{SpO}_{2}$ in newborn infants is difficult.

Objectives To determine whether a device that displays trend lines, reduced deviation from $\mathrm{SpO}_{2}$ targets during resuscitation of very preterm infants after birth.

Methods In a single-centre study, deviation from the $\mathrm{SpO}_{2}$ targets during resuscitation of preterm infants (gestational age (GA) $\leq 30$ weeks) with the aid of a newly developed graphical interface, displaying the trends of $\mathrm{SpO}_{2}$, fraction of inspired oxygen $\left(\mathrm{FiO}_{2}\right)$, was compared with current clinical practice. Data presented as median (IOR).

Results Ten infants (GA 274/7 (25-283/7) weeks, birth weight (BW) 812g (694-1068g)) were resuscitated using the graphical interface and 42 infants (GA 275/7 $\left(25 \%{ }_{7}-291 / 7\right)$ weeks, BW 930g (760-1148g)) were included in the control group. We found that infants resuscitated with the graphical interface spend less time above the $\mathrm{SpO}_{2}$ targets $(18 \%(4-24 \%)$ vs. $26 \%(13-42 \%))$, and had a smaller deviation during the time spend above the $\mathrm{SpO}_{2}$ targets $\left(2.3 \% \mathrm{SpO}_{2}(1.2\right.$ $\left.3.8 \% \mathrm{SpO}_{2}\right)$ vs. $\left.3.8 \% \mathrm{SpO}_{2}\left(2.5-6.3 \% \mathrm{SpO}_{2}\right)\right)$. Both time spend below the $\mathrm{SpO}_{2}$ targets $(29 \%(21-39 \%)$ vs. $24 \%(14-34 \%))$, and deviation below the target $\left(10.5 \% \mathrm{SpO}_{2}\left(8.3-25.9 \% \mathrm{SpO}_{2}\right)\right.$ vs. $7.1 \% \mathrm{SpO}_{2}$ $\left.\left(1.9-11.7 \% \mathrm{SpO}_{2}\right)\right)$ increased.

Conclusion The use of a graphical interface decreased high $\mathrm{SpO}_{2}$ levels during the resuscitation of preterm infants. However, both time spend and deviation below the $\mathrm{SpO}_{2}$ targets increased. It appears the current ERC guidelines are interpreted as the maximum acceptable $\mathrm{SpO}_{2}$, a target range would clarify the acceptable deviation

\section{THE RISK OF RE-OCCURRENCE OF CANCER TUMORS IN CHILDREN POST DIAGNOSIS AND TREATMENT}

doi:10.1136/archdischild-2012-302724.1553

E Odiase. Epidemiology, University of Ibadan/SmokeFree Foundation, Abuja, Nigeria

Background It is very imminent that the tissues of infants are immature thereby increasing the risk of re-occurrence of tumours after surviving cancer.

Methods This study was conducted for 6 years amongst 400 children who had earlier survived cancer and treated between 2005 2011 at the University of Ibadan Teaching Hospital (Paediatric ward). They were evaluated for re-occurrence of tumours.

Results The findings were that 5 re-occurrences were noticed in 6 of the children in a median time of 6 years. The 5 second malignancies were: 1 acute myeloblastic leukemia (AML), 2 breast cancers and 2 sarcomas. The primary diagnosis were Ewing's sarcoma, osteosarcoma, non-Hodgkin's lymphoma and neuroblastoma. Two of these children had received multiple therapies for recurrences. A Ewing sarcoma patient developed sarcoma after 4 years, an osteosarcoma patient developed breast cancer after 4 years, an ALL patient developed Ewing sarcoma after 3 years, a mesenchymal chondrosarcoma patient developed breast cancer and osteosarcoma. A soft tissue sarcoma, and an osteosarcoma developed in two bilateral retinoblastoma patients, a sarcoma developed in a rabdomyosarcoma patient after 6 years and in a patient treated for nasopharyngeal carcinoma after 3.5 years all in the radiation field. 
An extremity osteosarcoma developed in another bilateral retinoblastoma patient after 4 years.

Conclusions Since, the risk of this re-occurrence is associated with the dose of some chemotherapeutics cumulatively, the radiation field and the use of minimal therapy that has the maximum efficacy according to the diagnosis, age, stage and risk of the patient is important.

\section{AN EDUCATIONAL PROGRAMME FOCUSING ON PAEDIATRIC FRACTURE IDENTIFICATION MAINTAINS A LOW FALSE-NEGATIVE RADIOGRAPH INITIAL REPORT RATE IN EMERGENCY MEDICINE}

doi:10.1136/archdischild-2012-302724.1554

T Fox, A Rowland. Paediatric Emergency Department, North Manchester General Hospital, Pennine Acute Hospitals NHS Trust, Manchester, UK

Introduction False negative radiograph reports constitute greater than $80 \%$ of all diagnostic errors in Emergency Departments (EDs) with reported levels of false negative initial reports around 1\%.

Method The records of all patients recalled to the Emergency Department clinics for management of a possible false-negative initial radiograph report were examined $(n=46)$, following which the junior emergency medicine doctors received three tutorials on fracture identification and management. A re-audit was completed.

Results Between $1^{\text {st }}$ September 2010 and $16^{\text {th }}$ January 2010 a false negative radiograph report rate of $0.72 \%$ was identified. There were proportionally more false negatives in patients aged under 16. Between $16^{\text {th }}$ January and $31^{\text {st }}$ May 2011, after the educational intervention, the false negative radiograph report rate had dropped to $0.62 \%$. The percentage reduction in false negative reports was $13.8 \%$ $(\mathrm{p}=0.53)$.

Conclusions These results suggest that a well developed educational programme is an effective way of maintaining a low level of false negative initial reports in an Emergency Department.

False negative reports were most likely in fractures of the foot, wrist, elbow and those in the paediatric population. Educational sessions should focus on identification of these fractures. Mistakes in diagnosis can occur when an inexperienced clinician dismisses a positive clinical examination after mis-interpreting an imaging investigation. Encouraging senior review of paediatric radiographs could help to maintain a low false-negative report rate.

This study indicates that educational interventions may have the potential to improve patient care in the Emergency Department setting. Further ways to reduce human error need to be explored.

\section{A REVIEW OF SAFEGUARDING DOCUMENTATION IN PAEDIATRIC TRAUMA PATIENTS}

doi:10.1136/archdischild-2012-302724.1555

${ }^{1} \mathrm{~A}$ Mirdin, 'A Kent, ${ }^{1} \mathrm{AS}$ Lindsay, ${ }^{2} \mathrm{M}$ Vaidya, 'A Parikh. 'Paediatric Emergency Department; ${ }^{2}$ Paediatric Critical Care, Barts Health NHS Trust, London, UK

Background The Royal London Hospital is a Major Trauma Center (MTC) in East London. In 2011, we saw approximately 300 paediatric traumas. Our borough has one of the highest rates of safeguarding issues in the country. Therefore, awareness and documentation of these issues is paramount.

Aim To determine the quality of safeguarding documentation in paediatric trauma patients presenting to the Major Trauma Centre (MTC).

Methods A retrospective analysis of documentation of paediatric trauma patients notes presenting to the Emergency Department at the Royal London Hospital between 1st January 2011 and 1st January 2012. A register of patients was obtained from the Emergency Department database and trauma database. There are no current UK guidelines regarding minimum standards of safeguarding documentation in the paediatric population in the UK. We defined the audit standard as the minimum level of documentation required to satisfy Barts Health NHS trust and local policies.

Results Projected results indicate safegaurding documentation may be inadequate in greater than $90 \%$ of cases.

Conclusions Current standards of safeguarding documentation within our Major Trauma Centre will be significantly below the minimum standard required at a local level. This has implications nationally where analysis would be expected to achieve a similar outcome.

\section{A PROSPECTIVE REVIEW OF NITROUS OXIDE SEDATION POST INTRODUCTION OF A PAEDIATRIC PROCEDURAL SEDATION PROGRAMIME IN A PAEDIATRIC EMERGENCY DEPARTMENT}

doi:10.1136/archdischild-2012-302724.1556

1,2S McCoy, ${ }^{1} \mathrm{D}$ Barrett, ' $\mathrm{S}$ Walsh, ${ }^{1,2,3 \mathrm{R}}$ 0'Sullivan. 'Department of Emergency Medicine, Paediatric Emergency Research Unit (PERU), Our Lady's Children's Hospital; ${ }^{2}$ National Children's Research Centre; ${ }^{3}$ Department of Paediatrics, University College Dublin, Dublin, Ireland

Background and Aims Introduction of a structure Paediatric Procedural Sedation (PPS) Programme facilitates Emergency Department (ED) staff in the safe and efficacious practice of PPS in the ED. Methods Nitrous oxide was introduced into our institution in July 2011, as part of a PPS programme in the ED. All ED staff (doctors and nurses) must complete the sedation programme before preforming any sedation in the ED. Each sedation event is prospectively recorded on a specific paediatric emergency department sedation checklist and recorded data is then entered into a Microsoft Access ${ }^{\circledR}$ database.

Results Since the programme introduction 82 sedation events have been recorded. The majority of patients were male (49:33 M:F) with an average age of 6 years (17months - 15yrs). The indications for sedation were as follows: Joint manipulation (17), Removal of Foreign Body (12), Suturing (45) and Other (8). We have recorded a total of $17(20 \%)$ adverse events: most commonly, vomiting and agitation. The majority of procedures were performed by ED staff, however some required a specialist to perform the procedure: Plastic Surgery, General Surgery and Orthopedics. Without the provision of sedation in the ED the majority of these patients would have required hospital admission for general anaesthesia.

Conclusion The introduction of nitrous oxide as a sedative agent for procedures in children in our ED has been successful. With low adverse event rates which are comparable to international experience and no serious adverse events have been noted.

\section{IMPLEMENTATION OF A PROCEDURAL SEDATION PROGRAMME IN A TERTIARY PAEDIATRIC EMERGENCY DEPARTMENT}

doi:10.1136/archdischild-2012-302724.1557

1.2SC McCoy, 'D Barrett, 'S Walsh, 1,2,3R 0'Sullivan. 'Department of Emergency Medicine, Paediatric Emergency Research Unit (PERU), Our Lady's Children's Hospital; ${ }^{2}$ National Children's Research Centre; ${ }^{3}$ Department of Paediatrics, University College Dublin, Dublin, Ireland

Background and Aims In the conduct of Paediatric Procedural Sedation (PPS) within the Emergency Department (ED) the combination of powerful drugs, variable competency levels and high staff turnover carry the potential for sedation-associated adverse events. Yet, currently, there is no set programme for education and accreditation of Irish ED staff in PPS. We describe the introduction of a structured educational programme for PPS within the ED for all ED clinical staff. 